Thorax (1955), 10, 53.

\title{
SARCOMA OF THE OESOPHAGUS
}

BY

\author{
D. MILLAR BELL
}

From St. Bartholomew's Hospital, Rochester

(RECEIVED FOR PUBlication AUGUST 28, 1954)

Cases of sarcoma of the oesophagus are comparatively rare. It has been estimated that they account for $8 \%$ of all sarcomata of the alimentary tract (Corner and Fairbank, 1904).

The first case was described in 1877 (Chapman, 1877), the sarcoma arising from the inferior constrictor of the pharynx. Thorek and Neiman (1950) collected 58 cases from the literature $(30 \%$ fibrosarcoma, $8 \%$ leiomyosarcoma, 5\% lymphosarcoma, 5\% melanosarcoma, 3\% rhabdomyosarcoma, and seven unclassified).

From the clinical point of view Feldman (1948) differentiates three types: (1) polypoid, which may be either sessile or pedunculated, (2) diffuse, which simulates carcinoma, and (3) annular.

The polypoid type is said to be non-invasive and to metastasize late, while the diffuse type is invasive and metastasizes early. These tumours cause intermittent dysphagia, and pain is said to be more common than in cases of carcinoma (Neil and Horne, 1953).

\section{Histology}

The polypoid group is a spindle-cell sarcoma, and is probably genuine sarcoma, while the ulcerative group is a round-cell tumour and strongly resembles embryonal carcinoma in gross appearance (Ewing, 1940).

\section{Site OF Origin}

Sarcoma of the oesophagus commonly arises from the anterior wall of the oesophagus, the thoracic oesophagus being the common level.

It is usually single, either intra- or extra-mucosal, and often extra-luminal (Feldman, 1948). Treatment may be either surgical excision or some form of radiation, for example, deep $x$-ray therapy. The first successful resection was reported by Clark (1949) for a case of fibrosarcoma. Thorek and Neiman (1950) reported a case of rabdomyosarcoma successfully resected and the patient was alive one year later. Another case has been reported symptom-free 15 months after deep $x$-ray therapy (Dvorak).
A further case of fibrosarcoma of the oesophagus is now reported, the patient being alive and well one and a half years after deep $x$-ray therapy.

\section{Case History}

A woman aged 64 years was first seen by me on October 7, 1952, complaining of loss of appetite and weight for the past 10 months, with difficulty in swallowing for one week at the onset. Also, she had had pain in the lower dorsal region of the back for six months.

On clinical examination no abnormal physical signs were detected apart from the fact that the patient was very pale and rather thin. A provisional diagnosis of carcinoma of the fundus of the stomach was made.

A blood count gave 2,560,000 R.B.C.s, Hb 27\%, colour index $0.52,8,600$ leucocytes (normal differential count).

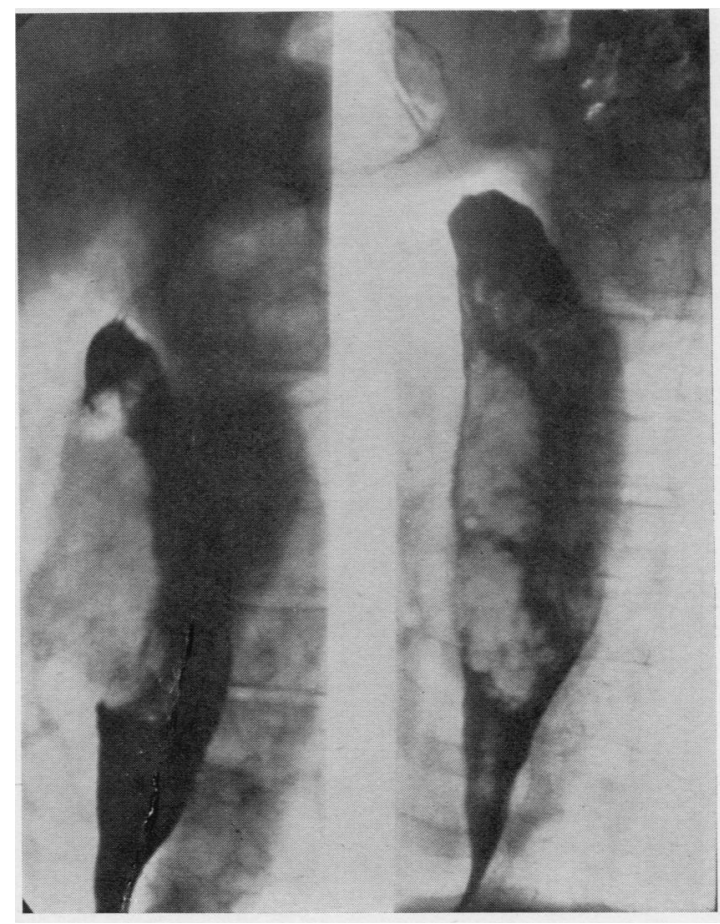

FIG. 1 


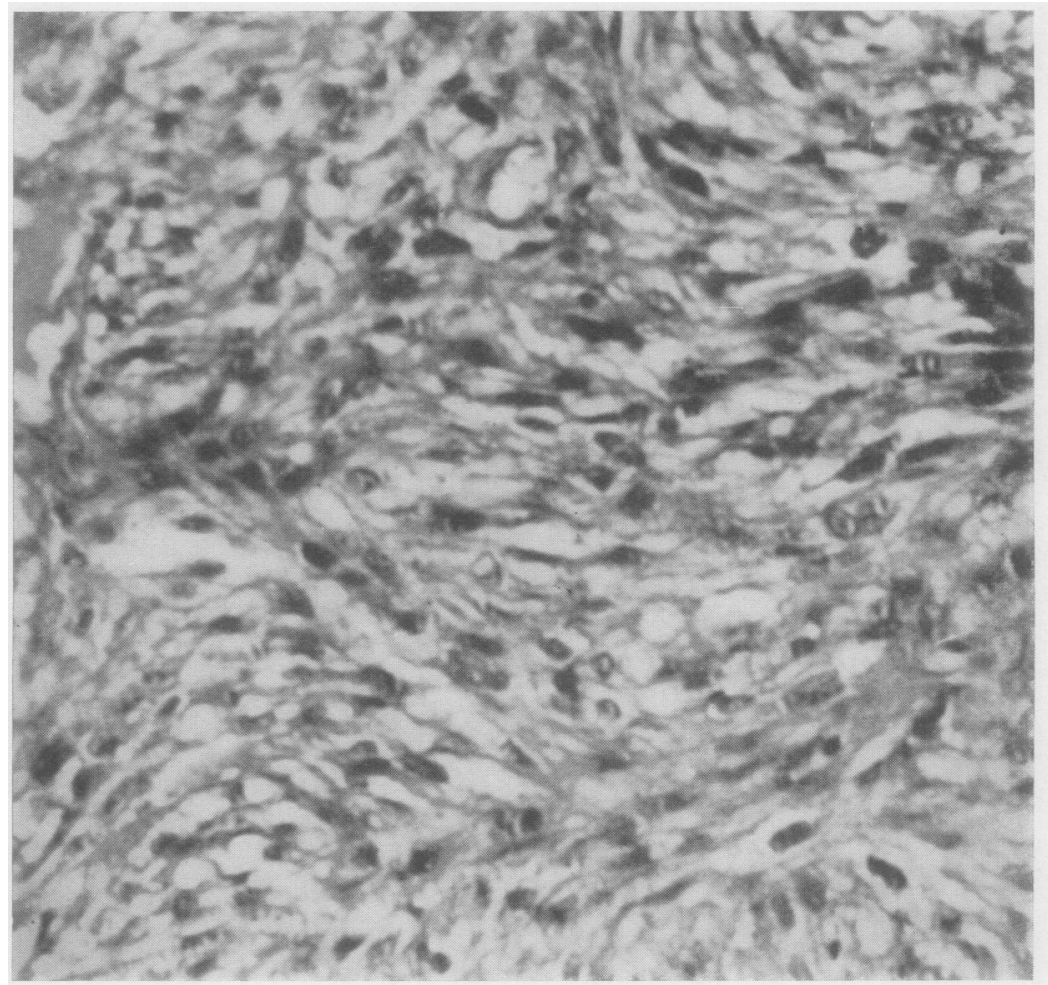

FIG. 2

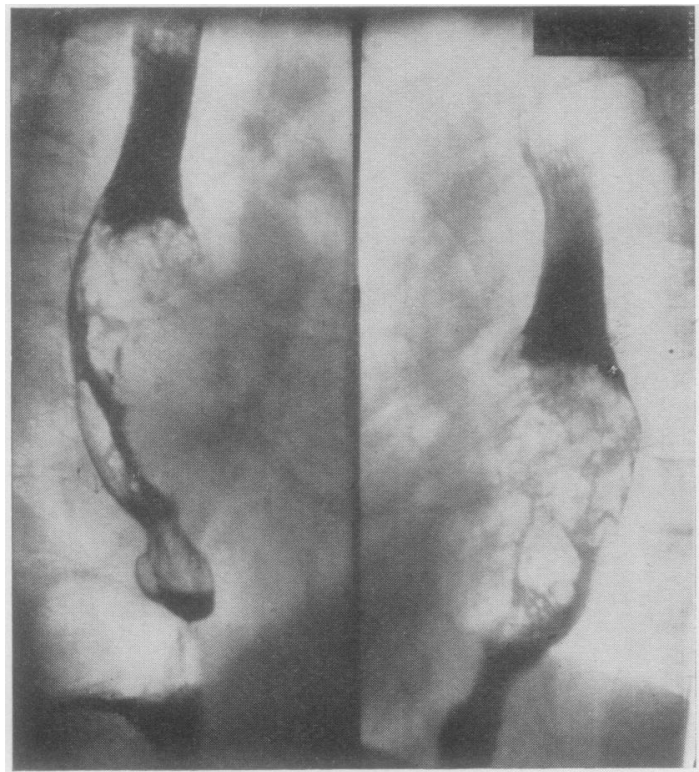

FIG. 3

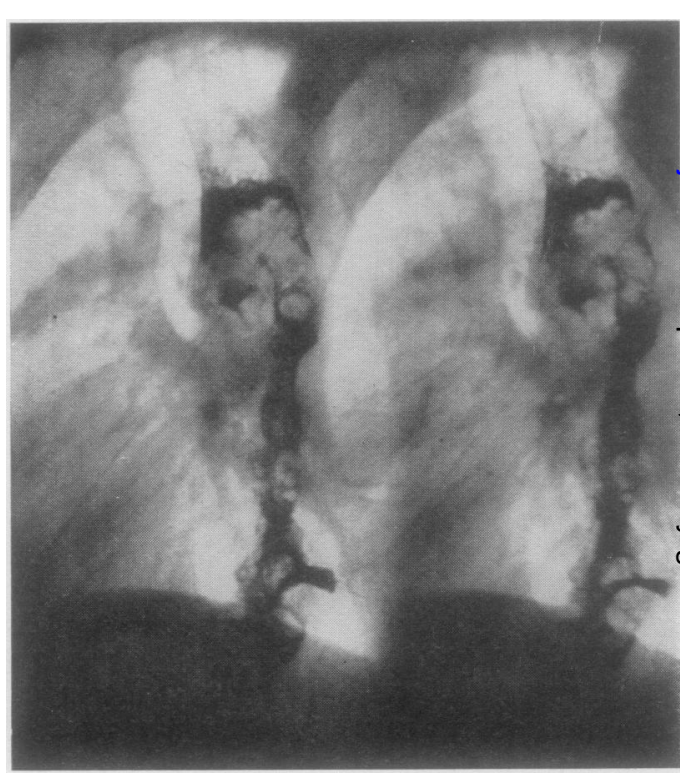

FIG. 4 
The result of a barium swallow is shown in Fig. 1. The middle and lower thirds of the oesophagus were dilated and showed a large irregular filling defect with much splitting of the barium. No pulmonary pathology was seen on a radiograph.

On oesophagoscopy a large friable growth was found $26 \mathrm{~cm}$. from the upper teeth. This was covered with blood clot. No attempt was made to pass the oesophagoscope through the friable mass because of the danger of perforation. A large piece was removed for histological examination.

The histology of the tumour is illustrated in Fig. 2, and the diagnosis was fibrosarcoma of the oesophagus.

The patient was admitted on November 17, 1952, and thoracotomy advised. Operation was refused. A transfusion of 3 pints of blood was given.

A course of deep $x$-ray therapy was given over two fields, 2700r to each field, and the patient was then allowed to go home.

The patient was seen regularly at the follow-up clinic. On February 11, 1953, a barium swallow gave the picture shown in Fig. 3. The lesion in the oesophagus was now much larger, with a very narrow, irregular lumen. The tumour appeared to be arising from the anterior wall of the oesophagus.

On May 27 the patient said that she felt very weak and had vomited blood copiously, this being followed by frank melaena for the next two or three days. She had no difficulty in swallowing. She was readmitted, obviously very weak, pale, and thin, with a red cell count of 2,280,000 and $\mathrm{Hb} 21 \%$.

A blood transfusion was again given and now the patient agreed to operation.

Mr. G. Townsley operated on June 16, 1953. A left thoracotomy was performed. A large growth was found in the middle third of the oesophagus, just below the arch of the aorta, extending into the hilum of the left lung, across the mid-line, and fixed posteriorly. The lower third of the oesophagus appeared normal. No resection was attempted.

The patient had an uneventful convalescence and was discharged on July 4 , when she said she felt much better.

She was seen again in August and December, 1953. She had had no difficulty in swallowing but had vomited blood on two occasions. A barium swallow on September 24 is shown in Fig. 4. The lesion has now extended down to the lower third of the oesophagus. There is a diverticulum-like pouch in the lower third which may be a small abscess cavity following a perforation at this site.

\section{COMMENTARY}

There are several points in this case which are worthy of note.

The patient is alive and well two and a half years from the onset of symptoms and one and a half years from the time of treatment by deep $x$-ray therapy.

Dysphagia is relatively slight. The patient was quite definite about it ; she had dysphagia for one week only at the onset. It is difficult to understand this fact in view of the presence of a large growth in the lumen of the oesophagus with much narrowing and distortion.

Haematemesis and melaena from a lesion in the middle third of the oesophagus is strange. One can readily accept the haematemesis, but it must be very rare to get such profuse bleeding from this level as to give melaena.

The breaking up or "splitting up " of the barium by the growth has been noted previously (Feldman, 1948). Allison (1942) has described it as "the peculiar soap bubble appearance."

\section{SUMMARY}

A short review of the literature on sarcoma of the oesophagus is given. A further case of fibrosarcoma of the oesophagus is described and the interesting features commented upon.

I wish to thank Mr. G. Townsley for his help and permission to report this case, and Dr. J. Corall for the radiographs.

\section{REFERENCES}

Allison, P. R. (1942). J. Laryng., 57, 218.

Chapman, S. H. (1877). Amer. J. med. Sci., 74, 433.

Clark, D. E. (1949). Arch. Surg., Chicago, 59, 348.

Corner, E. M., and Fairbank, H. A. T. (1904). Lancet, 1, 1503.

Ewing, J. (1940). Neoplastic Diseases, 4th ed. Saunders, Philadelphia and London.

Feldman, M. (1948). Clinical Roentgenology of the Digestive Tract, 3rd ed. Ballière, Tindall \& Cox. London.

Neil, J. F., and Horne, E. A. (1953). J. Laryng., 67, 159.

Thorek, P., and Neiman, B. H. (1950). J. thorac. Surg., 20, 77. 